\title{
Developing a Guidance Document to Improve Public Health Surveillance during Disasters
}

\author{
Nicole Nakata*1 and Amy Wolkin ${ }^{2}$ \\ ${ }^{1}$ ORISE Research Participant at CDC, Atlanta, GA, USA; ${ }^{2} \mathrm{CDC}$, Atlanta, GA, USA
}

\section{Objective}

Our objectives are to describe and receive feedback on a disaster surveillance guidance document that can be used by state and local health departments, to fill the gaps in public health $(\mathrm{PH})$ disaster morbidity and mortality surveillance.

\section{Introduction}

During all phases of the disaster management cycle, PH surveillance plays a valuable role. Surveillance provides $\mathrm{PH}$ officials and stakeholders the information they need to respond to disasters and take action in an appropriate and timely manner. Despite the fact that surveillance provides a valuable function in disasters, a study by the Disaster Epidemiology Subcommittee of the Council of State and Territorial Epidemiologists (CSTE) found that there are still significant differences, across states, in their use of disaster surveillance ${ }^{1}$. Further, there is no standardized guidance on implementing or modifying surveillance for a domestic disaster. This document seeks to fill this gap, providing guidance on planning, initiating, conducting, and evaluating disaster $\mathrm{PH}$ surveillance in the U.S.

\section{Methods}

We developed a draft disaster surveillance guidance document based on general PH surveillance best practices as well as recommendations for epidemiologic activity from disaster response handbooks, field manuals, and other government and non-governmental organization documents. We are also seeking input from stakeholders, including CSTE and ISDS. During this presentation we will present the concept of our draft disaster surveillance guidance document. We will give a brief overview on the following document sections: 1) introduction and purpose of disaster surveillance, 2) disaster surveillance systems and practices for implementing them, 3) analysis and dissemination of data, and 4) evaluating the effectiveness of disaster surveillance systems. We will also discuss useful resources such as standardized documents for data collection to include in the guidance.

\section{Results}

We hope to gather feedback to better understand what tools and resources are needed to increase disaster surveillance capacity and action. This will enable us to gather valuable input from our stakeholders, strengthen our document, and ensure we are meeting the needs of our state and local health departments. We also hope to increase awareness of and improve surveillance tools to aid in planning for and implementing disaster surveillance.

\section{Conclusions}

As disasters continue to occur with increasing magnitude and frequency, the use of this disaster surveillance guidance document may help state and local health departments plan for and implement $\mathrm{PH}$ disaster surveillance. Additionally, the use of standardized data collection forms and case definitions may aid in providing data useful beyond the response phase of a disaster for comparison and further study in the future.

\section{Keywords}

disaster surveillance; disaster management; guidance; morbidity; mortality

\section{References}

1. Simms E, Miller K, Stanbury M, Heumann M, Miller T. (2013) Disaster Surveillance Capacity in the United States: Results from a 2012 CSTE Assessment, Council of State and Territorial Epidemiologists. Accessed 7 February 2014 from http://c.ymcdn.com/sites/www. cste.org/resource/resmgr/EnvironmentalHealth/Disaster_Epi_ Baseline731KM.pdf

\author{
*Nicole Nakata \\ E-mail: wng9@cdc.gov
}

